\title{
Investigations into Mechanisms of Involvement of Objects and Personnel in Lightning Disasters
}

\author{
S. Murali Das* , G. Mohan Kumar and S. Sampath ${ }^{\S}$ \\ Centre for Earth Science Studies, Thiruvananthapuram 695031, India
}

\begin{abstract}
Cloud to ground lightning causes damage to objects and injures people by different mechanisms like direct hit, contact voltage, side flash, step voltage etc. Understanding the different ways of involvement of objects and personnel in lightning disasters is helpful in deciding the type and level of external protection. Details of investigations conducted in 47 lightning disasters spread over several years are presented. The different types of mechanisms of involvement of objects and personnel in these incidents are discussed. All the incidents investigated were from Kerala, India which is a region of relatively high vegetation density. In $51 \%$ of the cases objects and personnel were found to have got involved by ground conduction of lightning energy into dwellings. Some of the cases of ground conduction involvements are unusual. The high degree of damage in some of the unusual cases is attributed to the continuing current component. The role of metal objects in charge collection and dissipation is also discussed. The relative importance of ring conductor to the lightning conductor in places of high vegetation density is brought out.
\end{abstract}

Keywords: Ground conduction, continuing current, ring conductor, lightning disaster.

\section{INTRODUCTION}

A lightning incident becomes a disaster when it causes destruction of property and injury to people. Lightning disasters occur mostly in cloud to ground (CG) lightning. In many cases the injury becomes fatal. Involvement of people and objects occur by different mechanisms like direct hit, contact voltage, flashover, step voltage etc. The different modes of involvement of objects and personnel in lightning accident are detailed in Lee [1]. Understanding the mechanism of spread of energy in a CG lightning accident is useful in determining the adequacy of protection measures adopted. The authors of this paper tried to understand the different ways of involvement of objects and personnel in lightning disasters. This was done from a number of investigations spread over a few years. All the lightning incidents investigated had occurred in a region of relatively high vegetation density. From the investigations an attempt is made to understand the relative importance of lightning rod and ring conductor [2] for external protection. This paper discusses the investigations and results.

\section{MATERIALS AND METHODODLOGY}

\subsection{Data}

The data collected for the investigation are qualitative in nature. These are personal observations made at lightning accident sites. The investigation team visited forty seven accident sites to understand the mechanism of involvement of objects and personnel in lightning. The sites were not

\footnotetext{
*Address correspondence to this author at the Centre for Earth Science Studies, Thiruvananthapuram 695031, India;

Tel: +91 471-2511642/2511637; Fax: +91 4712442280

E-mail: muralidas_s@rediffmail.com,muralidass@gmail.com

${ }^{\S}$ Present Address: D227, Swathi Nagar, Thiruvananthapuram- 695023, India
}

selected ones but were those which could be reached without much lapse of time after the incident so that required evidence could be seen. Also many of the visits were made to investigate the truth of complaints or fear expressed by the people about the location being a 'lightning prone' one. The districts in which the accidents happened, the different modes of involvement of objects and the acronyms used for both are given in Table 1. Given in Tables 2-5 are the lightning disasters investigated. Upon visiting an accident site reports of earlier incidents were also collected. Such multiple event reports come during investigations against alleged 'lightning prone' locations. From such reported earlier events, the plausible events are also considered for the investigation. In some such cases, as seen in the tables, the exact date of incident is not available. However the most important aspect is that the investigators have visited all the sites of accidents even though in some cases after a long delay. In other words accidents that came to notice by hearsay alone are not considered here.

\subsection{Deduction of Course of Events in a Lightning Disaster}

In investigating an incident the primary aim was to locate the point or object on which the lightning struck. After locating the point of strike, the mode of propagation of lightning energy to different points of destruction or mode of involvement of objects and personnel in the vicinity is deduced. For example if a tree and an adjoining house with its electrical equipment are involved, first of all evidence for the point of contact is sought. The possibility of the tree being the one hit is considered by first considering the height difference between the two. Here the distance or closeness of the tree and house are considered. If the point or part of the house involved is shorter than the tree and if the part falls with in the $60^{\circ}$ angle from the tip of the tree then it is possible that the tree was hit and the lightning spread 
Table 1. Given in First Column is the List of Districts where Investigations were Conducted in South to North Order

\begin{tabular}{|l|l|}
\hline \multicolumn{1}{|c|}{ Acronyms for District Names } & \multicolumn{1}{c|}{ Acronyms Used to Indicate Mode of Propagation of Lightning to the Victim or Object } \\
TRV - Thiruvananthapuram & CV - Contact voltage \\
KLM - Kollam & DH - Direct hit \\
ALP - Alapuzha & FO - Flashover \\
KTM - Kottayam & GC - Ground conduction \\
IDK - Idukki & SF - Side flash \\
EKM - Ernakulam & SV - Step voltage \\
PKD - Palakkad & \\
KZH - Kozhikode & \\
\hline
\end{tabular}

The acronyms used in text for the districts are given here. In the second column acronyms used to indicate the mode of involvement of objects in an accident are listed.

through some path to the house. Further evidence for charred marks or other aspects of tree top having had the hit is looked for. Similarly evidences of damages to the building for having had the discharge are looked for. In most of the cases of lightning hits to trees, burnt marks or charred leaves could be seen. In the case of coconut trees and other monocotyledon trees the tender bunch of leaves could be seen spoilt and hanging down, next day, instead of standing vertically up. Also slightly reddish coloured fluid will be seen to seep out from a large number of points on the trunk. In some cases coconut trees have been found to split open as a result of an inside explosion along the length. In many cases of ground conduction clear marks of ground propagation from a tree base to the nearest point of basement of the nearby house could be seen. In some such cases the soil was found to have blown away leaving a ' $v$ ' shaped channel of one to two inches width on the ground.

\subsection{Geographical Region and its Characteristics}

All the accidents investigated had happened within the state of Kerala in India. The state of Kerala is located between latitudes $8^{0} 22^{\prime} \mathrm{N}$ to $12^{\circ} 50^{\prime} \mathrm{N}$ and longitudes $74^{0} 50^{\prime} \mathrm{E}$ to $77^{\circ} 28^{\prime} \mathrm{E}$ and is geographically divided into three regions along the length. The division is by the height above mean sea level (AMSL) and the first one namely the low lands, has an altitude less than $8 \mathrm{~m}$ AMSL. This division is mainly comprised of coastal plains. The second namely the mid lands fall in the height range from $8 \mathrm{~m}$ to $75 \mathrm{~m}$ and the third namely the high lands are above a height of $75 \mathrm{~m}$. The state is bounded in the west by the Western Ghats mountain range which is included in the highlands. The state is divided administratively into 14 districts.

Kerala is a place of relatively high lightning incidence in India $[3,4]$. Real time statistics is presently not available.

\subsection{Soil Characteristics and Vegetation Cover}

The coastal region mainly has alluvial soil with water bed only a few metres below and because of this, the soil conductivity in general is relatively higher than the other two regions of the state [5]. Near rivers riverine alluvium is present. This is a type of soil developed along river valleys and occurs throughout the state cutting across laterite soil. Laterite soil is a weathered product and occurs throughout the state and has conductivity different from that of coastal alluvium and hard rock. Soil classified as forest loam formed from weathered crystalline rocks occurs in the eastern part of the state. However midlands and high lands generally have laterite and granite below the surface with water table in most places being at a depth of several tens of meters. In the northern parts of Kerala the low lands also has granite below the surface. Summing up, the conductivity of the soil has a wide variation from highly conducting alluvial soil to relatively low conductivity soil containing exposed rock in the high lands. The events investigated fall in all these regions of differing soil conductivity. The soils at locations of lightning disasters presented here have been classified into three classes of conductivities as low $(l)$, medium $(m)$ and high $(h)$. The alluvial soil of resistivity up to $800 \mathrm{Ohm} \mathrm{m} \mathrm{[6]}$ is classified as one with high conductivity. Soils with resistivity from 800 to $5000 \mathrm{Ohm} \mathrm{m}$ is classified as of medium conductivity and soils of resistivity above 5000 $\mathrm{Ohm} \mathrm{m}$ is classified as one of low conductivity. Rocky areas with thin soil cover is classified as ground with low conductivity and those places having conductivity that falls midway between this and high conductivity alluvial soil have been classified as medium conductivity soil. However the conductivity attributed to the soil at the accident sites are not blindly based on this classification as the resistivities vary greatly depending on type of soil and water content [7]. The water table depth at the time of incident, water holding capacity of the soil, specific type of soil at the location, rock being visible at the surface and other related aspects are noted during visit to the accident site in determining the class of conductivity of the soil. After considering all these aspects and the known characteristic of the region from earlier surveys ${ }^{1}$ the conductivity of soil at the site is decided.

The study area, namely Kerala, has some difference in vegetation characteristics relative to adjoining areas in India. It has a forest cover of about $28 \%$ and an average vegetation density of about $85 \%$ inclusive of mixed cultivation [8]. However it is a region where dwellings are almost surrounded by a wide variety of trees. Coconut, areca nut, palm, rubber, teak, acacia, jack fruit, mango, anjili, elavu, choonda pana are some of them. In some of the districts especially in the eastern parts rubber cultivations with houses among them is a common sight. Similar is the case of coconut trees in most parts of the state. This aspect of vegetation density is a significant one for the investigations and conclusions presented here.

\footnotetext{
${ }^{1}$ John Mathai, Scientist, Geo Sciences Division, Centre for Earth Science Studies, Akkulam, Thiruvananthapuram, India, 2007. Personal communication; email: mathaicess@cessind.org
} 


\section{INVESTIGATIONS AND RESULTS}

The districts where the investigated accidents occurred and their acronyms are present in Table $\mathbf{1}$. The order of the list of districts is from south to north. Thiruvananthapuram is the southern most of the districts.

Depending on the primary mode of conduction of lightning energy, the events have been grouped into four. Each group of accidents are presented separately.

\subsection{Group A Disasters - Accidents by Side Flash and Flashover}

These accidents are listed in Table 2. In the accidents listed with site numbers from A1 to A8, the main modes of involvement were side flash or flashover. That is, the object or person got involved in the accident by lightning flashing over from the first object hit.

In accidents $\mathrm{A} 1$ and $\mathrm{A} 2$ flashover occurred from an electric wire coming from outside the building. At A1 the mishap occurred in a newly built house. Flashover occurred from a twisted pair wire used for taking power connection from an old house nearby. Lightning hit the wire which was out in the open. A child standing near the wall socket to which the twisted pair was connected was injured fatally. There was a neat circular mark of soot of about $1.25 \mathrm{~m}$ in diameter, caused by the explosion, around the wall socket. Possibly through the flashover the child became a conducting path to earth. In the old house also power wiring and some electrical equipment were damaged. At site A2 it was an antenna wire coming from the roof of the building to the TV inside. Lightning hit the antenna and there was a flashover to a girl. Here also it seems the girl became a conducting path to earth. In both cases the victims were near the wire at the time of lightning strike. At A2 the victim survived after treatment. In both cases the copper conductor of the wires were missing.

The A3 accident was caused by a side flash to a child standing close to a tall jack fruit tree which was hit. One side of her body had severe burn marks. The injury was fatal and the tree was also destroyed.

At site A4, lightning seems to have hit a house inside which was the victim. The laterite brick walls of the house seem to have become live with lightning energy. There was a reinforced cement concrete (RCC) slab protruding into the kitchen from the wall at a height of about $1.6 \mathrm{~m}$. A girl standing near it with her head only a centimetre or two from the tip of the slab was injured fatally by flashover to her head. Visible head injury was present. The report was that a small portion of the head had blown off. Explosive injury seems to have happened on the head of the victim due to Joule heating as mentioned in Rakov and Uman [9]. The tip of the RCC slab was found broken exposing the steel rod inside with charred marks being present near the broken off portion. Two short and young coconut trees $3 \mathrm{~m}$ away on the same side of the house were also destroyed possibly due the potential gradient on ground.

At A5 and A6 several people were injured by side flash and step voltage from a tree hit by lightning. At A5 the victims were in a thatched shed in a school, where a tree was one of the supporting poles and it was hit by lightning. A teacher standing near the tree was injured fatally by side flash and 5 students in the same class were injured by step voltage. People injured at A6 were standing near two closeby palm trees, attending a funeral when lightning struck the trees. They were crowding inside a small thatched shed close to the palms and so were well in contact with one another. The people were taking shelter from rain which had just begun. One survivor reported having burn injury almost all around his waist, probably because of his body being in contact with many. The trees bore long, charred, length wise marks of side flash. Twenty three people were injured of which six were fatal. Here contact voltage and side flash seems to have been the mechanism of connection from the trees to the people crowding around them. The number of casualties became high because of the contact among the group. Since the funeral was that of a squadron leader, Air Force personnel present at the funeral gave first aid to the victims which saved a few. Without first aid the number of casualties could have been higher. As the palms were close together it was difficult to decipher whether only one was hit or not. Both the palms were destroyed.

The accident at A7 happened on a river bank. On the bank there was a large rock which was cut and flattened to the level of the other portions of the bank. This rock had a concave formation extending to the farther elevated sideways

Table 2. List of Disasters where the Deduced Mode of Conduction of Lightning Energy was Side Flash or Flashover

\begin{tabular}{|c|c|c|c|c|c|}
\hline Site No. & $\begin{array}{l}\text { Date of Accident } \\
\text { (D-M-Y) }\end{array}$ & $\begin{array}{c}\text { District } \\
\text { (Acronym) }\end{array}$ & $\begin{array}{l}\text { Type of Terrain \& Class of } \\
\text { Conductivity (Type-class) }\end{array}$ & $\begin{array}{l}\text { Inside or Out Side \& } \\
\text { Type of Building }\end{array}$ & $\begin{array}{c}\text { Mechanism of Energy } \\
\text { Propagation (Acronym) }\end{array}$ \\
\hline A1 & $14-$ Oct-97 & KLM & Hilly-m & RCC roof & FO \\
\hline A2 & 28-Mar-02 & TRV & Hilly- $m$ & $\mathrm{RCC}$ roof & FO \\
\hline A3 & 14-Nov-96 & KLM & Hilly $-m$ & Outside & $\mathrm{SF}$ \\
\hline A4 & 10-Nov-97 & ALP & Alluvium- $h$ & Partial RCC & FO \\
\hline A5 & 4-Oct-99 & $\mathrm{KZH}$ & Hilly-l & Thatched & SF, SV \\
\hline A6 & 15 -Oct-00 & PKD & Hilly-l & Outside & $\mathrm{SF}, \mathrm{CV}, \mathrm{SV}$ \\
\hline A7 & 8-Apr-02 & TRV & River bank- $l$ & Outside & $\mathrm{FO}, \mathrm{SV}$ \\
\hline A8 & 9-Apr-01 & TRV & Midland- $m$ & Tiled roof & $\mathrm{FO}, \mathrm{CV}$ \\
\hline A9 & Mar-2003 & TRV & Alluvium- $h$ & $\mathrm{RCC}$ roof & SF \\
\hline
\end{tabular}


extent of the river bank. The victims of this incident took shelter from rain under the concave rock formation. Over the concave formation was present 'Pongu', a soft wood tree which was hit by lightning. Two people were injured by side flash and step voltage. Injury to one of them was fatal. The deceased was closer to the vertical portion of the rock and was standing. Through side flash his whole body was involved in the current flow. Later, the other person, who was injured by step voltage, reported seeing arcing on the flattened portion of rock surface. The tree survived the lightning hit.

At site A8 several people and equipment in houses within a few square kilometres were affected by lightning spreading through over head land telephone network. At one accident site within this location the damage to the phone network was heavy indicated by disappearance of junction boxes and wires. Close to this site, in one thatched house a lady trying to switch on an electric lamp was electrocuted by flashover from the switch board. Her blouse got scorched from the flash and she was hospitalised for two days. In this house the power supply wire from the nearby electric supply post was intact. This house did not have a phone connection. Hence it is deduced that the lightning energy has conducted from the nearby telephone pole through ground to this house and its wiring. The possibility is that the lady became a conducting path between ground and the power wiring of the house. Rest of the affected houses in this accident site had telephone connection. In all those houses because of proximity of telephone and power wiring, equipment connected to both lines were destroyed. Here, electrical wiring and equipment which were close to the telephone equipment and its wiring only were destroyed. In all these houses flashover could have happened to the power wiring from the telephone lines. One more person was injured by contact voltage at this site as he was holding the telephone receiver at the time lightning struck. This house is about $1.5 \mathrm{~km}$ away from the lady's house. Summing up this is a disaster of involvement of several houses through a hard wired telephone network.

The incident at site A9 was relatively an uncommon one. The incident happened near one of the authors' house and happened at about $1900 \mathrm{~h}$ local time. From the evidences seen on the morning after, the event is deduced to have happened as follows. Lightning hit a relatively short and young coconut tree. There was flashover from the tree trunk to an over head power distribution line as the tree trunk was close to the line. The tree trunk had a length wise gash with the fibrous wood bulging out caused possibly by an explosion. The explosion could have happened due to heating by a higher or longer duration continuing current $[9,10]$. The tree was damaged and was felled next day morning. The lightning energy which entered the power line involved the power distribution box of the nearest house, burnt the power meter, main switch gear etc. For the lightning discharge, it seems the ground connection was established by arcing to the earthed metal body of the power meter. Metal cover of the power meter got melted possibly because of the arcing to the phase or neutral wire which had the lightning voltage. There was a hole of about $2 \mathrm{~cm}$ width by $4 \mathrm{~cm}$ length on the power meter casing and molten metal was found strewn inside the meter board enclosure. The hole could have formed due to a long duration continuing current as suggested in Rakov and Uman [9]. Neither the wiring nor any other household electrical equipment had any damage. Upon establishing a connection to the earthed metal casing of the power meter through arcing, the difference voltage caused by lightning was not high enough to cause any damage to the house wiring or equipment. The power earth point of the house was just below the power meter. This earth connection seems to have provided a sufficiently good conducting path for lightning currents and seems to have resulted in protecting the house wiring and electrical equipment inside it.

\subsection{Group B Disasters - Accidents by Contact Voltage}

Details of accidents presented as group B disasters are given in Table 3. At sites B1 to B4 the victims of accidents got injured by being in contact with a wall, tree or some similar objects which were hit by lightning or was in good contact with a lightning hit object.

At B1 a person was untying a calf from a tree which was hit by lightning. He must have got injured by contact voltage. The possibility of injury to the person by step voltage also cannot be ruled out.

At site B2 two people, one sitting on the door step and another touching the wall of an asbestos roof auditorium died. The victim who was sitting had burn injury on head and heel by contact with the wall and floor. The person who was leaning on the wall had burn on one side. A third person injured did not have burn marks but was reported hospitalised and discharged after two days. It was reported that he had some heart problem developed due to lightning injury. Possibly he was also injured by contact voltage and might have suffered ventricular fibrillation [1]. The auditorium had large RCC windows with honey comb structure. Cement covering over the steel of the honey comb structure was found blown off from some of them

Table 3. List of Disasters where the Deduced Mode of Conduction of Lightning Energy was Through Direct Contact with an Object which was Hit

\begin{tabular}{|c|c|c|c|c|c|}
\hline Site No. & $\begin{array}{c}\text { Date of Accident } \\
\text { (D-M-Y) }\end{array}$ & $\begin{array}{c}\text { District } \\
\text { (Acronym) }\end{array}$ & $\begin{array}{c}\text { Type of Terrain \& Class of } \\
\text { Conductivity (Type-class) }\end{array}$ & $\begin{array}{c}\text { Inside or Out Side \& } \\
\text { Type of Building }\end{array}$ & $\begin{array}{c}\text { Mechanism of Energy } \\
\text { Propagation (Acronym) }\end{array}$ \\
\hline \hline B1 & 2-May-95 & KLM & Hilly- $m$ & Outside & CV, SV \\
\hline B2 & 7-Apr-02 & TRV & Plains- $m$ & Asbestos \\
\hline B3 & Mar-01 & IDK & Hilly-l & Outside & CV \\
\hline B4 & 15-Mar-03 & IDK & Hilly-l & Partial RCC & CV \\
\hline B5 & 8-Apr-98 & ALP & Alluvium- $h$ & Partial RCC & CV, SV \\
\hline
\end{tabular}


which indicated that the walls were live with lightning discharge currents.

At location B3 a lady was injured fatally inside a thatched shed. She had chest and neck burn injuries. She was electrocuted from lightning while putting a cloth for drying over a wooden partition sort of a thing. The partition was attached to a wall of the shed. The wiring inside the shed was destroyed. There is a possibility that a tree nearby was hit and the shed became live due to ground conduction. Even though the location had lot of trees like jack fruit tree, the one hit by lightning could not be located. So the investigators were forced to believe that the lightning hit the shed.

At B4 a person was using a table which was in contact with one wall of a room when lightning hit the building. He walked to the next room and collapsed. Possibly he was electrocuted by the difference voltage between the wall and ground by contact through the table. The incident at site B5 was a difficult one to deduce. The house hit was a partial RCC one with the kitchen and chimney having RCC roof. Chimney is the tallest part of the building. The victim was inside the kitchen trying to close the door when lightning struck. She was thrown off possibly by contact voltage through the shutter of the door. Passage of electricity is known to cause muscle contractions [1]. Possibly the lady was 'thrown off' due to muscle contractions. A glass pane of the kitchen window also was found broken. The broken glass pane can be considered as an indication that there was shock on the wall either by shock wave or by vibration induced due to the lightning hit on the chimney or RCC roof. A coconut tree a few metres away from the other end of the house which is about $20 \mathrm{~m}$ from where the lady was, was also hit. The possibility of the main discharge having hit the chimney and a branch of the stroke having hit the taller object, the coconut tree, is also to be considered. The reverse, that is, the branch of lightning hitting the chimney is also possible. As the distance of the tree from the asbestos roof is more than $20 \mathrm{~m}$ the flashover from the tree to the roof is not considered.

\subsection{Group C Disasters - Accidents by Direct Hit}

Accidents by direct hit are grouped as Group $\mathrm{C}$ disasters the details of which are given in Table 4.
In the $\mathrm{C} 1$ to $\mathrm{C} 9$ group of incidents people and objects were involved in lightning by direct hit. At location $\mathrm{C} 1$ a person walking towards his house to seek shelter from rain was injured fatally by direct hit as the space near the house was void of trees. One side of his body and face were found 'blackened'; it was reported. The person injured at C2 was on top of a coconut tree felling coconuts and upon hit by lightning fell all the way down and died. It is also possible that he was electrocuted by difference of voltage between his feet and hands.

At sites $\mathrm{C} 4$ to $\mathrm{C} 6$ three or four trees were involved in each incident. For convective thunder storms which is the most prevalent type of lightning source in Kerala [4] three to four trees getting damaged in an incident is normal. Multiple tree damage happens possibly by flashover between the trees and sometimes by branches of lightning simultaneously hitting them. In contrast to $\mathrm{C} 4$ to $\mathrm{C} 6$ accidents, the incidents at $\mathrm{C} 3, \mathrm{C} 8$ and $\mathrm{C} 9$ resulted in loss of several trees in one incident. From the time of the day and time of the year of happening of these incidents it is deduced that frontal thunderstorms could have caused them. At $\mathrm{C} 3$ fifteen young coconut trees of about $5 \mathrm{~m}$ height were destroyed in one incident. The trees are all monocotyledon trees and so destruction to the roots by step voltage seems to be a possibility as the top layers may be more affected during conduction of lightning. At C9 it was 13 trees of which 3 were coconut and rest were rubber. At $\mathrm{C} 8$ also the number of trees lost in one incident seems to be high. The exact number could not be obtained. Here also, as in $\mathrm{C} 3$ the thunderstorm was a frontal one. One common factor in $\mathrm{C} 3, \mathrm{C} 8$ and $\mathrm{C} 9$ is that the roots of the trees are similar in nature. It is well known that the roots of adult rubber trees are more or less fibrous, similar to those of coconut trees and not very deep like the tap root of a Jack fruit tree. Trees of such fibrous root system seem to be more vulnerable to step voltage than trees with tap roots.

At $\mathrm{C} 7$ there was no personal injury. Here lightning seems to have hit the antenna of a TV. The bamboo pole supporting the antenna broke and through the wire of the antenna it entered the house and caused damages to TV and other electrical equipment. Two days later a jack fruit tree a few meters away from the antenna showed signs of lightning hit. Some of the tree branches, below the top, were found dead

Table 4. List of Accidents where the Deduced Main Mode of Involvement was by Direct Hit

\begin{tabular}{|c|c|c|c|c|c|}
\hline Site No. & $\begin{array}{c}\text { Date of Accident } \\
\text { (D-M-Y) }\end{array}$ & $\begin{array}{c}\text { District } \\
\text { (Acronym) }\end{array}$ & $\begin{array}{c}\text { Type of Terrain \& Class of } \\
\text { Conductivity (Type-class) }\end{array}$ & $\begin{array}{c}\text { Inside or Out Side \& } \\
\text { Type of Building }\end{array}$ & $\begin{array}{c}\text { Mechanism of Energy } \\
\text { Propagation (Acronym) }\end{array}$ \\
\hline \hline C1 & Apr-2000 & IDK & Hilly-l & Out side \\
\hline C2 & 2-May-97 & IDK & Hilly-l & Tree top \\
\hline C3 & Jun-July 94 & EKM & Midland - $m$ & Outside & DH \\
\hline C4 & 1995 & EKM & Midland- $m$ & Outside & DH \\
\hline C5 & Oct-96 & EKM & Midland- $m$ & Outside & Outside \\
\hline C6 & May-99 & EKM & Midland- $m$ & TH antenna & DH \\
\hline C7 & $4-A p r-01$ & TRV & Hilly- $m$ & Outside- trees & DH, FO, SV \\
\hline C8 & 9-Apr-07 & KTM & Midland- $m$ & Outside- trees & DH, FO, SV \\
\hline C9 & $27-A p r-07$ & KTM & Midland- $m$ & \\
\hline
\end{tabular}


and dried up. In this case also, as in B5, it seems one branch of lightning has hit the tree simultaneously.

\subsection{Group G Disasters - Accidents Due to Ground Conduction}

The disasters grouped with site numbers from G1 to G24 are of importance in this paper. The list of disasters is given in Table $\mathbf{5}$.

In all these cases the victim or the object was not directly hit or was directly involved but were involved through ground conduction of lightning energy. All the incidents had happened inside buildings. These incidents are classified as ground conduction disasters because the people and property seems to have involved in these accidents by conduction of lightning energy through ground to objects inside the houses. In all these accidents some metal object or electrical wiring of the house was instrumental in involving the house and the people in it. In most of the incidents the conduit containing the cables of the power distribution network inside the houses were damaged. Also the poly vinyl chloride (PVC) insulation of the cables was found burst open. In some cases copper or aluminium conductor had disappeared by vaporisation due to intense heat. The characteristics of these disasters are:

1. In all the cases the damage or injury had happened inside a building.

2. In all the cases there was no direct lightning hit to the house but some tree or object outside was found to have had a lightning hit with substantial damage.

3. The incidents have happened in different types of houses. Some were of RCC roof, some tiled roof, some with asbestos roof and some other with thatched roof.

4. All the houses were electrified. The significance is that the house wiring seems to work like a good charge collector and dissipater as it is spread as a network to a large area of the house. Whether power supply was present at the time of accident or not is not a matter of serious consideration. Some had power supply at the time of incident while others did not have. Some houses had land telephone and these were also damaged. In one house it was the aluminium railings which caused the ground conduction into the house.

Table 5. List of Disasters where the Deduced Main Mode of Involvement was Conduction of Lightning Energy Through Ground

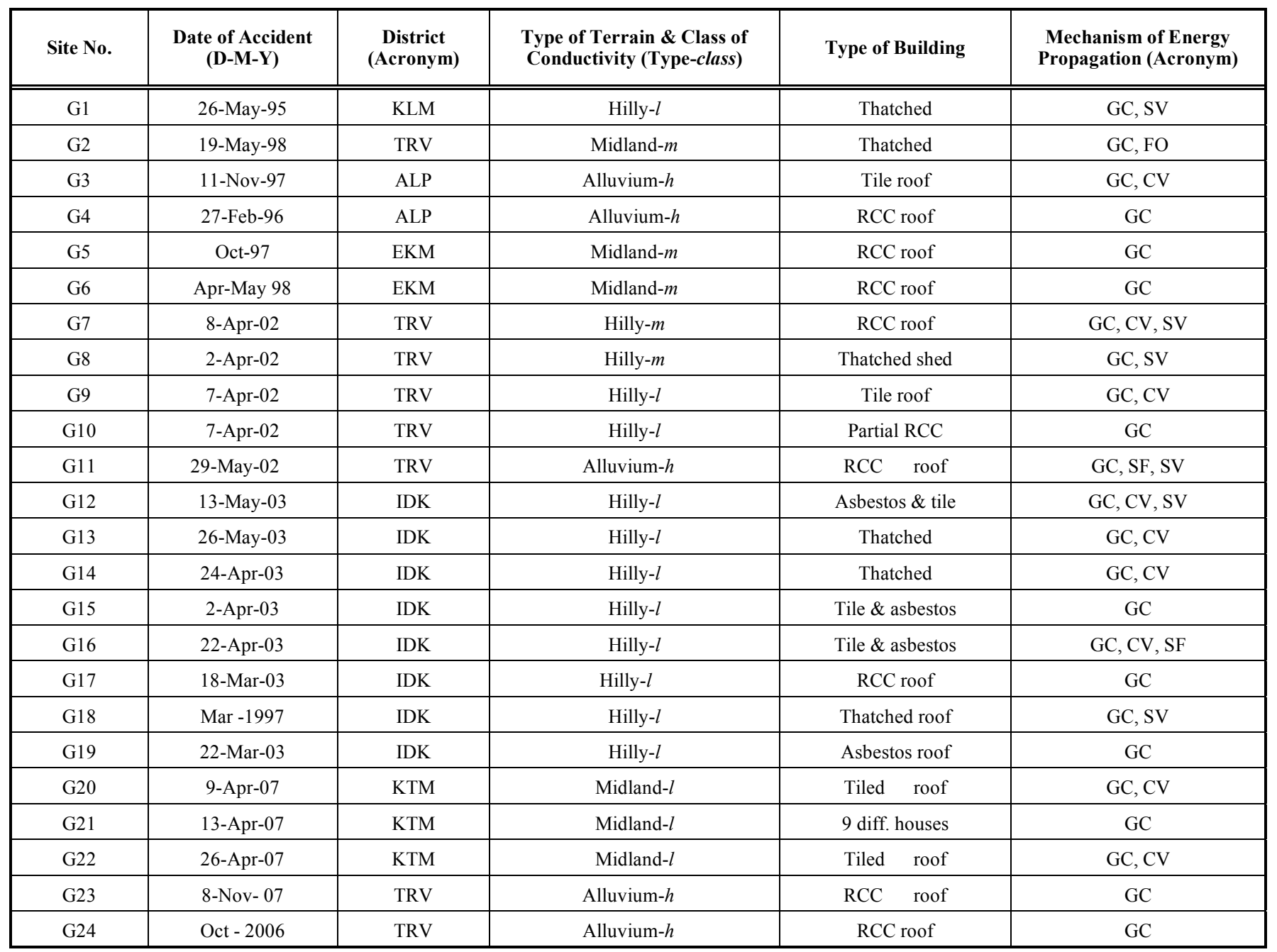

Here all the accidents had happened inside buildings. The mode of involvement of personnel inside the buildings upon the building becoming live by $\mathrm{GC}$ is also indicated in the last column. 
5. Internal power wiring and/or electrical equipment fitted to the wiring where ever available were damaged in 23 out of 24 cases.

The accidents at sites from G1 to G24 are discussed here in detail.

The G1 site is in an area in Kerala which has relatively more lightning incidence. Lightning seems to have hit a group of five isolated coconut trees. A thatched house which had power wiring was only $5 \mathrm{~m}$ away from the trees. In the accident the floor was cracked, and wiring destroyed. A person lying on the floor was injured due to step voltage between his head and feet. All the five trees were destroyed. A drawing of the site is shown in Fig. (1).

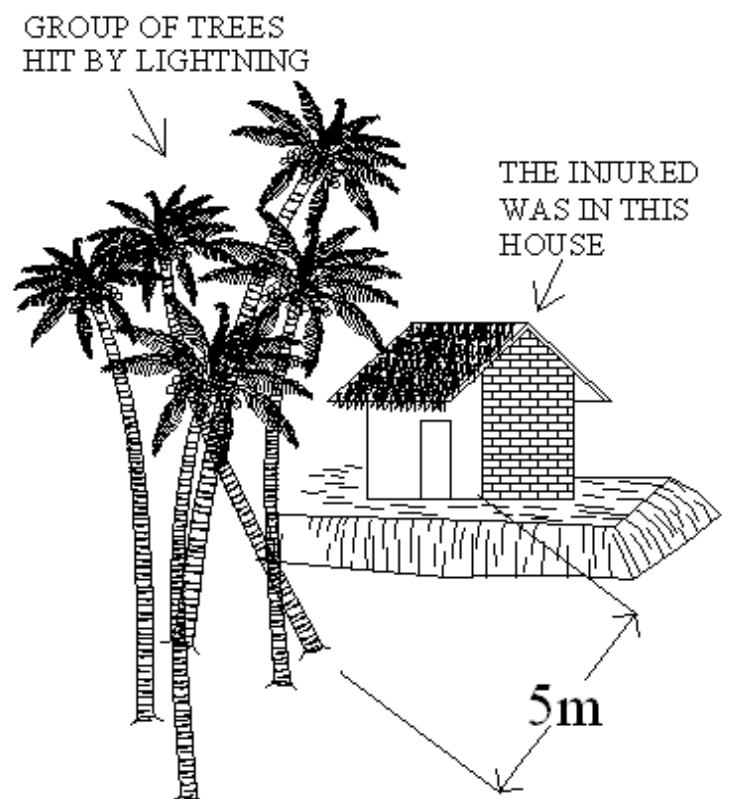

Fig. (1). Lightning accident through ground conduction from an isolated group of coconut trees to a house which had electric power wiring. Only these trees were present at the time of accident.

At $\mathrm{G} 2$ a tamarind tree $5 \mathrm{~m}$ away from the back door of a house was hit by lightning. A drawing of plan view and side view of the house with position of the victim at the time of lightning is shown in Fig. (2).

The house had electric power wiring with properly done connection from power meter board to a lamp $2 \mathrm{~m}$ away from it on the same wall. This was in the sit out. A second connection was given to another lamp in the living room using a thin PVC lamp flex (twisted pair) wire. This wire was hanging loosely to about $1.5 \mathrm{~m}$ height from the floor so that it could have touched any body passing by. At the instant the lightning struck, a girl was moving with a pan of water and was near the hanging wire. The wire exploded involving the girl by flashover. The possibility is that the energy spreading by ground conduction got connected to the wiring through the girl to the loosely hanging lamp flex. Through the lamp flex the lightning energy must have got connected to the power earth through the power meter board. Between earth connection and phase or neutral there must have been another flashover or insulation breakdown. In other words a significant component of the lightning discharge current must have flown from power earth and got connected to the tree through meter board, the lamp flex, through the body of the victim by ground conduction. Copper conductor of the lamp flex got vaporised and was missing. All the wiring of the house was destroyed. A ' $\mathrm{v}$ ' shaped channel was found from the base of the tree to inside the house. The house floor was made of mud plastered with cow dung mix so that the channel of conduction could be seen terminating near the living room-kitchen door. Here the tree was not destroyed.

At G3 accident site also a 'v' shaped channel was seen. Here it was on the soil outside the house. Lightning struck a tall isolated cotton tree (elavu) about $8 \mathrm{~m}$ away from the kitchen side of a house and spread through ground conduction to the power wiring of the house and destroyed it. The power wiring could be seen opened up and the multi strand copper conductors were looking somewhat like wire brushes caused by innumerable breaks. A drawing of the site G3 is shown in Fig. (3).

A person sitting on the floor of the kitchen was injured fatally. It was reported that he was crouching on the floor

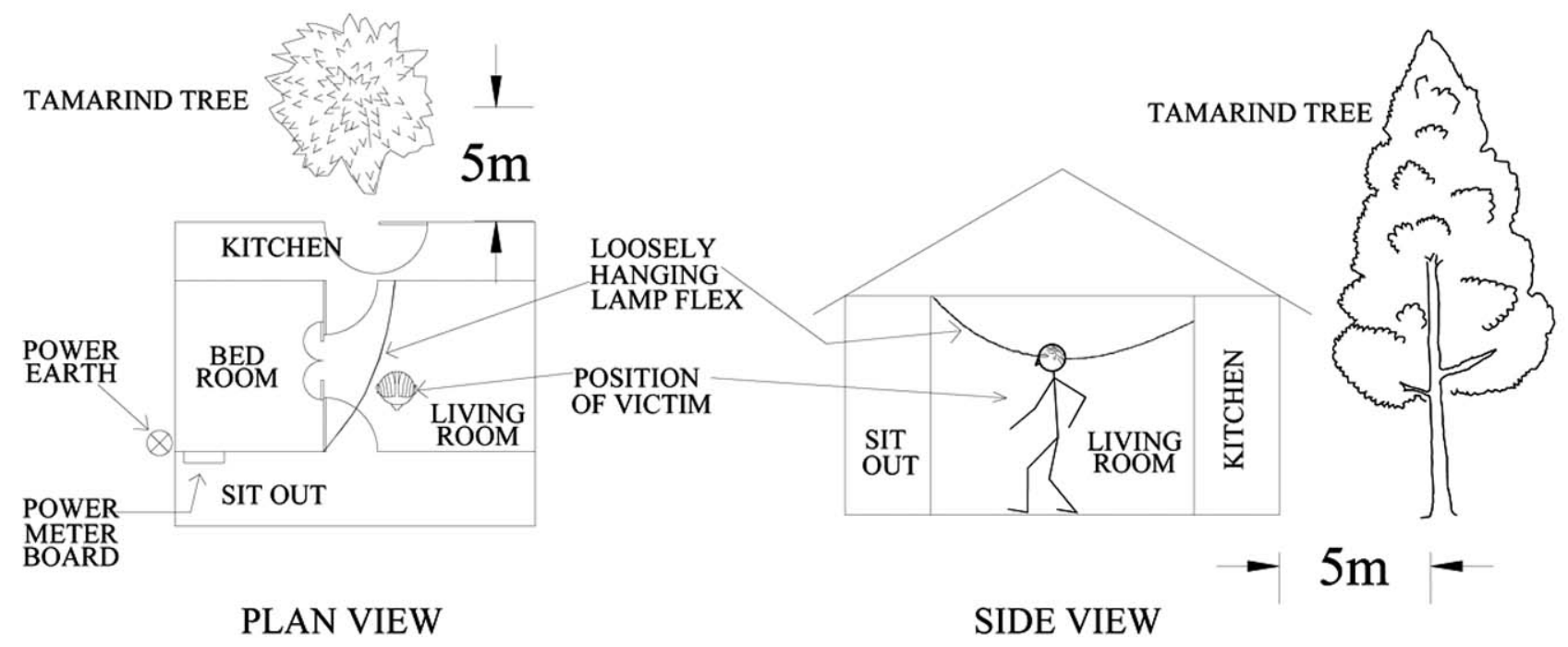

Fig. (2). Plan and side views of the G2 accident site showing the position of the victim at the time of lightning strike. Lightning hit the tamarind tree. Location of power earth is shown in plan view. 


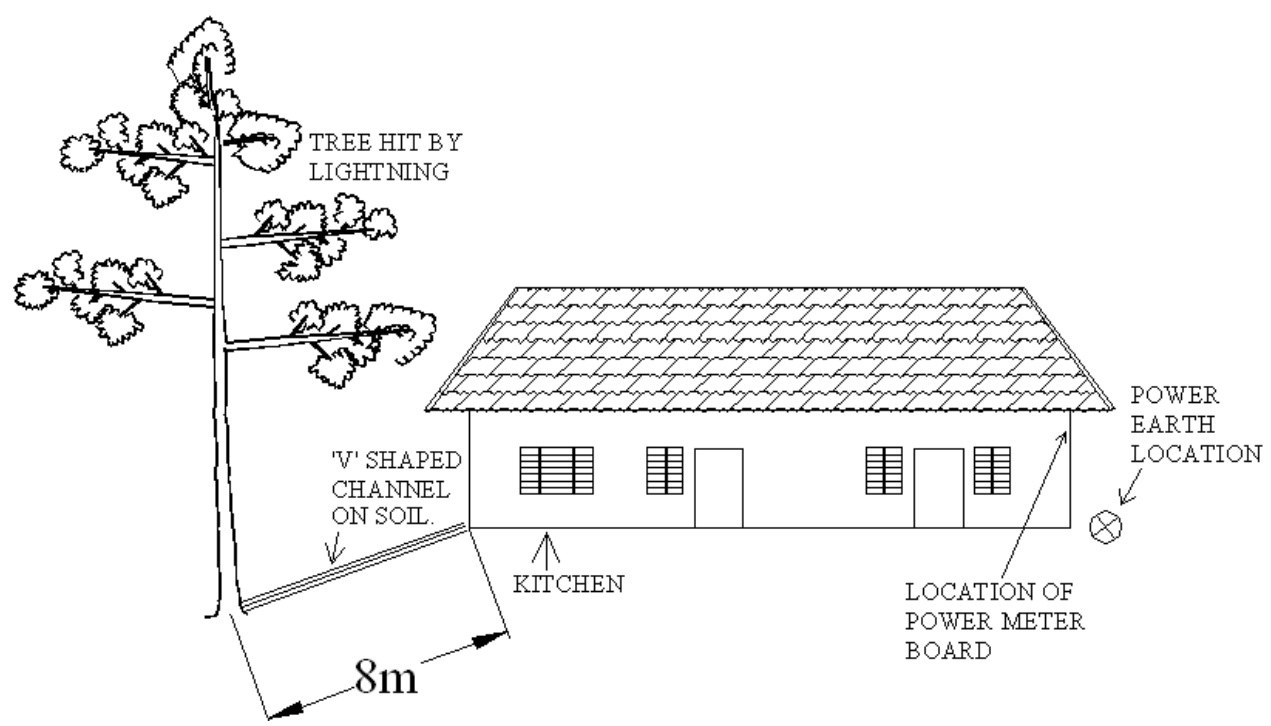

Fig. (3). Side view of the accident site of G3 indicating the tree hit by lightning and position of ' $v$ ' shaped channel on the soil. The tree was an isolated one.

and was eating food kept on an RCC slab at a height of about $0.75 \mathrm{~m}$. The RCC slab was on the wall, projecting inside from the kitchen wall. Probably the victim's body carried one of the branches of currents between ground and the wiring through the RCC slab by contact with the slab. The tree was destroyed. The power supply connection wire and the power meter board at the other end of the house were intact.

At G4 site some electrical equipment were damaged but condition of wiring could not be ascertained as the house wiring was of the concealed type. The coconut tree hit was about $5 \mathrm{~m}$ away from the building. The aspect of significance in this accident was that a piece of wood was reported to have blown off from the tree which was hit. This is an uncommon happening. The possibility is that the continuing current through the tree could have been relatively high or could have been of longer duration. This is an area with loamy soil with water table only a few meters below the surface. The high current could have caused an explosion as explained in Rakov and Uman [9]. The tree was destroyed.

Incidents at G5 and G6 happened at the same location except that events happened at two different times. The house involved is situated in a rubber plantation. Both times trees outside at distances of about $5 \mathrm{~m}$ and $10 \mathrm{~m}$ were destroyed. The trees were taller than the house. In both incidents the wiring of the house and some portion of RCC roof were damaged. The power supply wire to the house was running under the roof and close to it. Flashover from the wire to the roof caused the damage to the roof.

The distance through which the lightning energy conducted through ground at $\mathrm{G} 7$ was about $15 \mathrm{~m}$. A drawing of the accident site is given in Fig. (4).

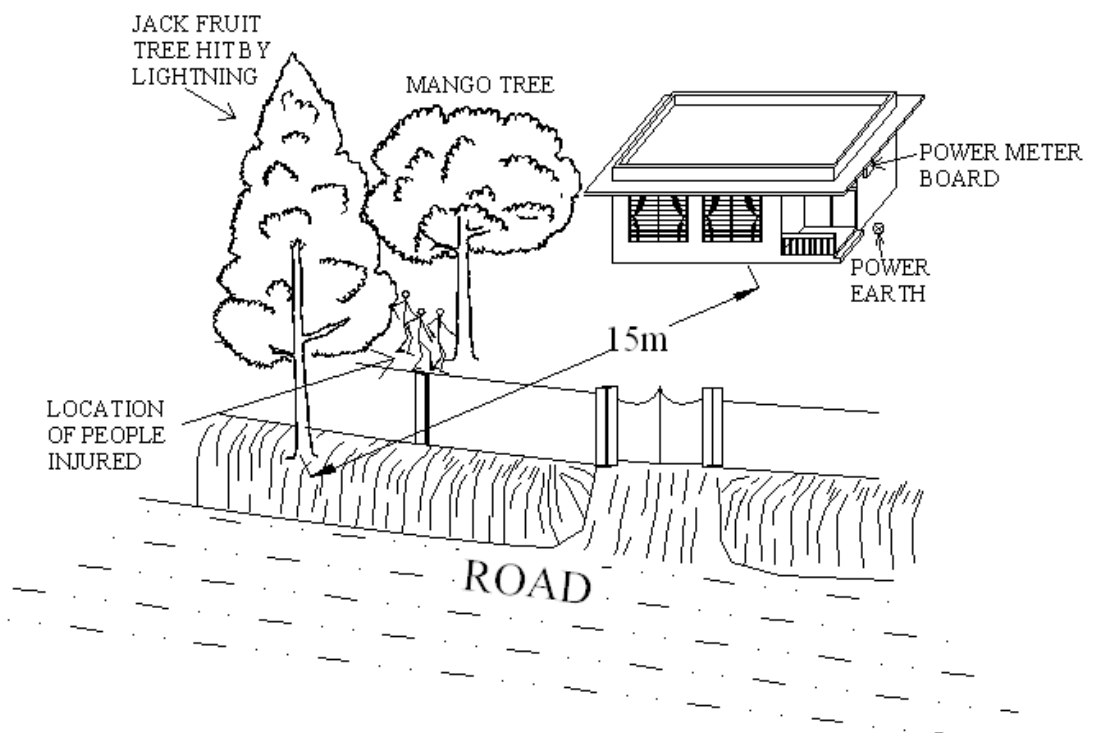

Fig. (4). A drawing of the G7 location indicating position of victims at the time the accident occurred. The jackfruit tree is relatively much taller than the mango tree. One of the injured was plucking mangoes from the tree with a pole while lightning struck. 
The power wiring in two rooms adjacent to the main power meter board, main meter board and telephone network of an RCC roof house was destroyed by ground conduction of energy. Lightning it seems hit a tall jack fruit tree which was on a road side as shown in the figure. This tree was just outside the compound wall of a house. The other side of the road sloped further down. Because of this height difference and presence of road the jackfruit tree essentially was an isolated tall tree vulnerable for lightning hit. Close to the wall and inside the compound wall was a much shorter mango tree, near which were three people standing close to each other. The leaves of the mango tree were touching the leaves of the jack fruit tree. One of the people was plucking mango from the tree using a pole at the time lightning struck. All the three were injured. The one who was plucking mangoes was injured fatally. The possibility is that the mango tree was live by contact voltage from the jack fruit tree and the fatally injured got electrocuted through the pole by contact voltage from the mango tree. The ground also was live and the other two must have got injured by step voltage. The bark of the jackfruit tree was found strewn around it exposing the inside cork cells. Removal of patches of bark are known to happen [11]. Both the trees were not destroyed in the incident.

The G8 incident was a relatively simple one where a coconut tree at a distance of about $5 \mathrm{~m}$ from a thatched shed was hit and a person inside was injured by step voltage caused by ground conduction. This shed was something like an out house and did not have power wiring. It is possible that in the absence of the shed also the victim could have been electrocuted by step voltage. This was the out house of the main building which is a tiled roof building. In the main building the land telephone was destroyed. The tree was also destroyed.

The G9 and G10 accident sites are close by. Injury and destruction at these two sites are from the same lightning which occurred at $1610 \mathrm{~h}$ local time. One person was injured in G10 location. The G9 and G10 sites are houses and are shown in Fig. (5).

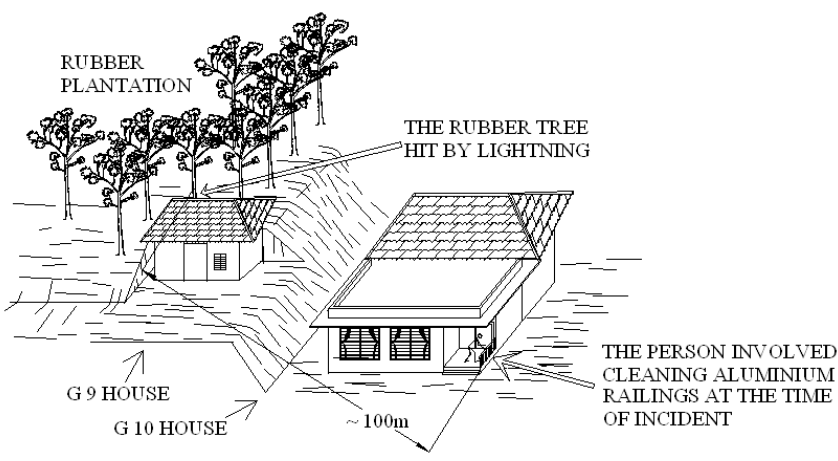

Fig. (5). A drawing of the G9 and G10 accident locations, which are houses.

The houses are near a rubber plantation. Lightning seems to have hit a rubber tree near G9. Five days later the rubber plant which was hit by lightning was found completely dead and another one next to it had a few branches dried up. Power wiring in the G9 house was damaged completely and switches and wall sockets in many rooms were blown off from the wall. The G9 house is about $3 \mathrm{~m}$ below the tree level because it is built on a cut on sloping ground. G10 is a partial RCC roof house which is about $100 \mathrm{~m}$ away from the tree which was hit. A lady who was cleaning the Aluminium railings in front of the G10 house was injured. No damage to power wiring or electrical equipment was reported in the G10 incident.

The incident at G11 happened due to lightning from a frontal cloud which is relatively very less in Kerala [4]. In a way the incident is slightly a peculiar one. This is an incident where side flash occurred to the roof of a house from a tree and simultaneously the house floor also became live through ground conduction. Shown in Fig. (6) is the disaster site and the incident is described below.

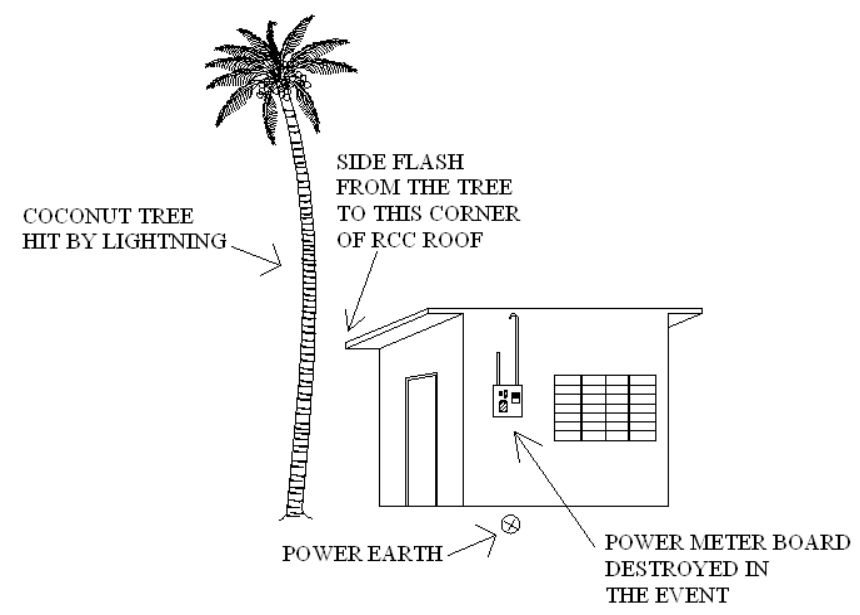

Fig. (6). Drawing of the site G11 showing the isolated coconut tree which was hit by lightning and the close by RCC building. The building and personnel inside were involved by side flash and ground conduction.

Lightning hit a tall isolated coconut tree only a metre away from an RCC roof house at about $0010 \mathrm{~h}$ local time. One corner of the RCC roof was close to the tree trunk by about a metre. Side flash seems to have occurred to the roof corner because the corner was found cracked exposing the steel rod inside. The tree was destroyed. The RCC roof seems to have become live and then through the walls lightning energy seems to have entered the electrical wiring of the house. The power meter board located on the opposite side and the whole wiring of the house were destroyed. Switch boards on the walls were blown off. It seems the lightning energy conducted through the power meter board to the power earth right below it. Simultaneously, it seems the ground also became live because three people sleeping on the floor were injured by step voltage between their heads and feet. The ground seems to have become live by ground conduction from the tree.

The sites G12, G13 and G14 are on a hill slope. It is a rocky terrain with low soil conductivity. It seems the low conductivity has facilitated ground conduction to a relatively longer distance. At G12 the house was at a distance of about $25 \mathrm{~m}$ from the tree which was hit by lightning. A line drawing of the accident location is given in Fig. (7).

The house wiring was damaged and one person lying on a cot touching the wall in the room nearest to the tree died. The possibility is that the difference voltage between the floor and the wall could have a caused a current flow 
through the victim's body. Another person lying on floor in the same room was injured by action of potential gradient between different points of his body. A third person on another cot in another room was thrown off the bed. Upon electrocution muscle contractions are known to occur. The person who fell off the bed could have fallen because of the muscle contractions. A cow in a cow shed at a distance of less than $10 \mathrm{~m}$ from the lightning hit tree was unharmed. It was reported that the cow was standing on a wooden platform. In the accidents discussed later, say G13, it can be seen that wood is not a saviour. In the present case also it seems the cow was saved probably because there was no metal object or wiring to involve it by ground conduction. Hence the potential gradient in the cow shed could have been very low. The power supply network inside the house was done through exposed PVC tubes fixed on the walls. The PVC tubes and the insulation of the cables inside were broken exposing the copper inside. The main fuse in the power meter board was found blown.

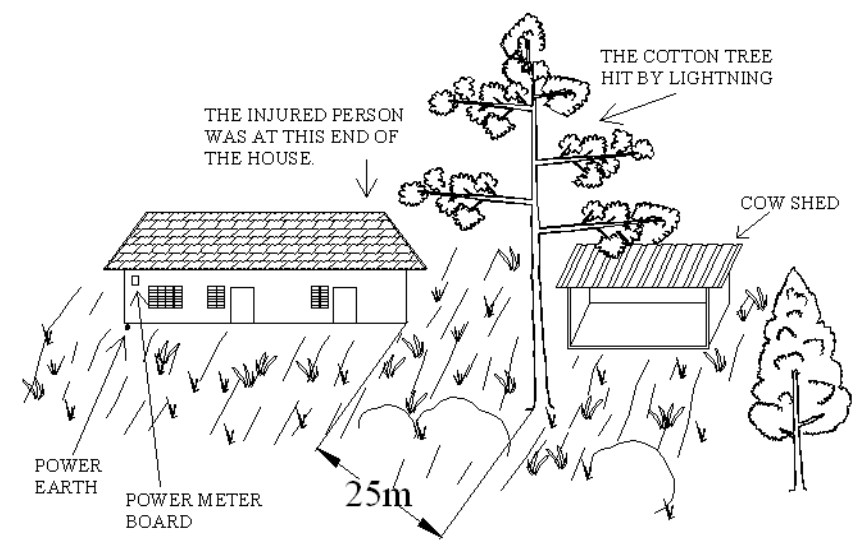

Fig. (7). Depiction of accident site G12. A person in the house was injured fatally.

At site G13 lightning struck a bamboo tree bunch. The bamboo bunch was found growing in the crevices of rocks. The rocks near the roots of the tree bunch bore somewhat greyish white marks indicating that ground arcing had taken place. The tree bunch is on a slope. Down below at a distance of about $20 \mathrm{~m}$ and a level difference of about $2 \mathrm{~m}$ is a thatched roof house with mud walls and floor. A rusted bicycle chain cover was lying on the ground near the side of the house facing the bamboo bunch. The scene of the accident is shown in Fig. (8).

A lady was sitting on a wooden cot, inside the house at the time of lightning strike. To be more specific the cot was at an angle and one end of the cot was touching the wall. The lady was sitting at the end of the cot which was closest to the wall. She was breast feeding her infant child. There were two other people sitting at the other end of the cot. The cycle chain cover was lying just outside the same wall. The discharge, it seems, established contacts with the chain cover, the injured lady and the electrical wiring of the house. While establishing contact with the power wiring of the house the lady seems to have become conducting path. The current flow caused a hole of about $10 \mathrm{~cm}$ diameter on the mud wall at about $0.3 \mathrm{~m}$ height above ground. The height of the cot was about $0.6 \mathrm{~m}$. The hole was right above the cycle chain cover. It is likely that the cycle chain cover was instrumental in supplying some amount of charges and also in establishing the route to the lady. Probably the lady's knee was touching the wall at $0.3 \mathrm{~m}$ height and her hand or so was touching the wall at a higher point. One of her feet could have been touching the floor also. The lady was injured fatally and the infant was not injured. As the greater proportion of the human body resistance is on the limbs [1] the infant who must have been in contact with the torso could not have experienced considerable difference voltage across it's body. Two other people sitting on the other end of the cot were also injured probably by the difference voltage between the floor and the cot. These two were injured, probably because the cot had current flow through it and so had potential difference relative to the floor. Here an aspect to be noted is that the cot, made of wood, was also live with the lightning energy. The wiring of the house was found destroyed. Window glass of the power meter box was found broken. Here, the metal cycle chain cover and the electric wiring of the house seem to have been instrumental in involving the house through ground conduction. The bamboo tree bunch did not show signs of destruction. Puffs of fibrous roots of the bamboo tree were found hanging on leaves at a height of $2.5 \mathrm{~m}$. This indicates that a small explosion caused by the continuing current had happened near the roots of the bamboo tree bunch.

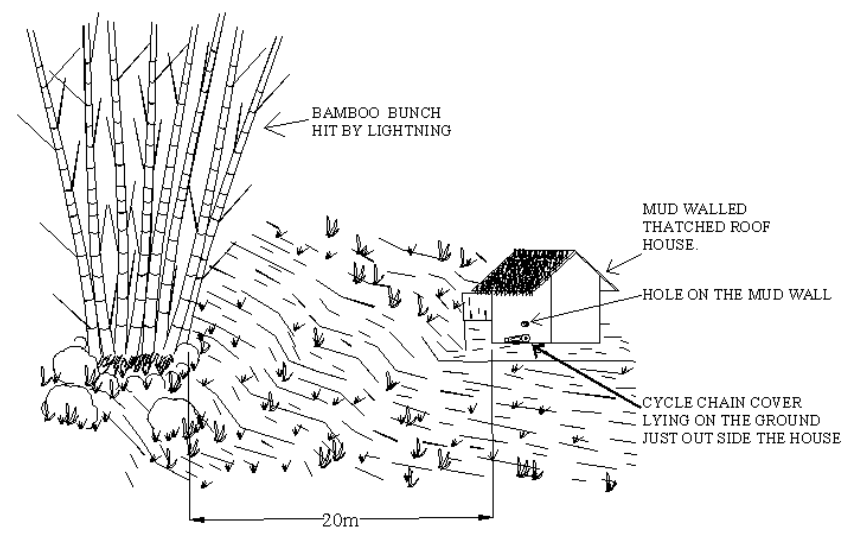

Fig. (8). The scene of the G13 accident. The position of the hole on the wall of the house is indicated. The fatally injured victim was on the other side of the wall. The bamboo bunch was not the only tree in the vicinity.

In the G14 accident the distance between the house involved and the tree hit by lightning was more than $50 \mathrm{~m}$. The whole area had lot of exposed rocks and wherever soil was present it was only centimetres thick over the rock. A drawing of the location showing the tree involved and the house are shown in Fig. (9).

There was only scanty soil seen on the surface near G14 which is an indication of low conductivity. This house also had power wiring. A small isolated tree growing in the crevice of a rock was hit and a person standing on the doorway of a thatched house was injured fatally. The victim had hip and hair burns. The incandescent bulb in the room was found broken. The tree was destroyed. The tree was only $3 \mathrm{~m}$ tall but was located at the corner of a steep ridge as shown in Fig. (9). The long distance of conduction in this incident is attributed to the low conductivity of the rock. 


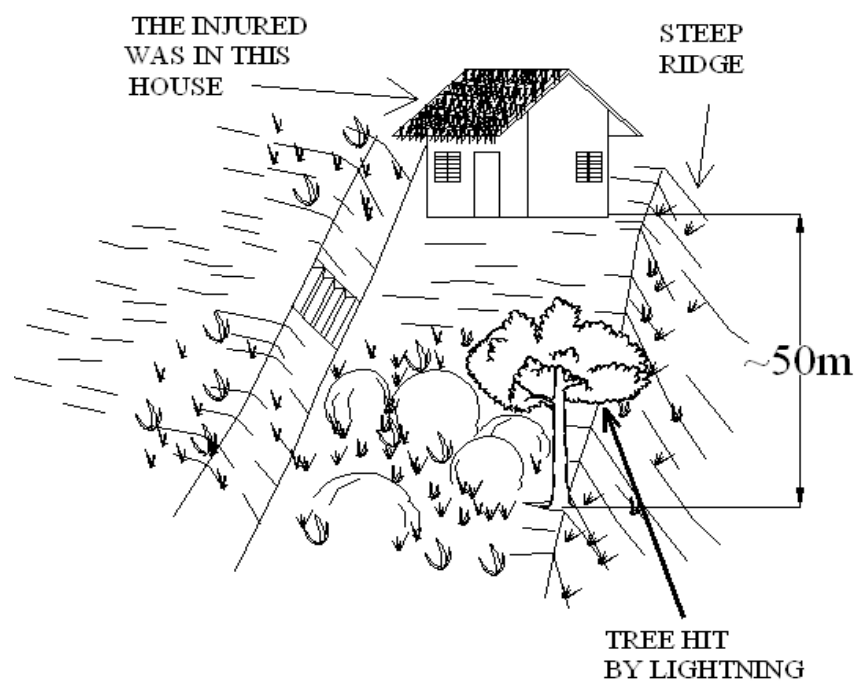

Fig. (9). Depiction of the accident site G14. The tree which was hit by lightning as shown in the figure was short, an isolated one and was growing in the crevice of a rock.

The accidents listed as G15 and G16 happened at the same location within a time difference of only 20 days. A drawing of the location with position of the victims at the time of incident is shown in Fig. (10).

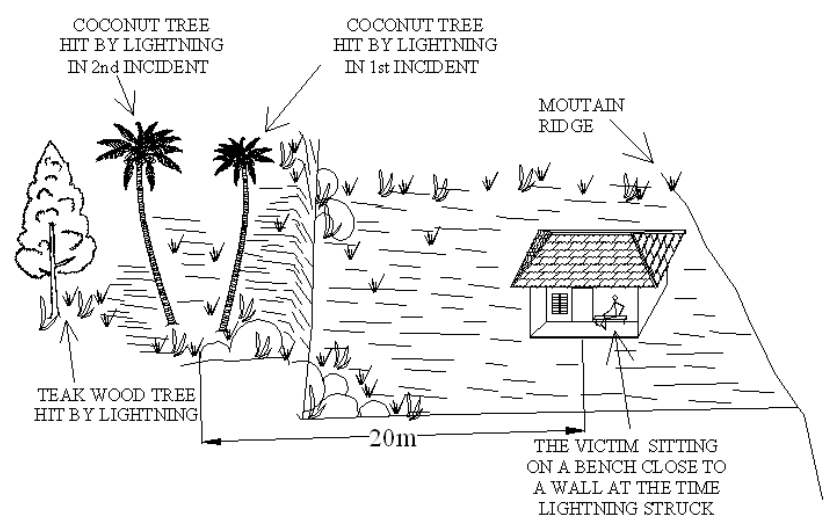

Fig. (10). Location of the two accidents G15 and G16. Both times the victims, first the husband and second time the wife were seated on the bench shown. The location is close to a steep mountain ridge.

First the head of the family was sitting on the bench and escaped with an injury to his eye brow. Second time it was his wife who got injured. She was wearing a gold chain around her neck and had an ear ornament too. She was sitting on the same bench at the same location. The bench was put close to a wall and so the victims could have been touching the wall or must have been was very close to it. The lady's injuries were to the spots where the ornaments were, namely the ears and the neck. The burn mark along the line of the neck chain could be seen by the investigators when they visited the site 43 days after the accident. Probably as described in Kitagawa et al. [12] the ornaments had triggered flashover to the live wall of the house. A coconut tree was hit in the first incident and was destroyed. Another coconut tree which was about $5 \mathrm{~m}$ away from the first one and a teak wood tree close to it were hit the second time. This coconut tree also was destroyed. The teak wood tree suffered only partial damage. Mountain ridges are known to be relatively vulnerable for lightning strikes [13]. It is possible that the site had two incidents within 20 days because of this characteristic of the location.

At the G17 location four coconut trees were destroyed by lightning strike. One of them was only $5 \mathrm{~m}$ away from an RCC roof building and some electrical equipment connected to power line like fan, light etc. in the building were destroyed by involvement through ground conduction.

The accident at site G18 was reported by the husband whose wife was fatally injured in a lightning accident. The house is a tiled roof one. One anjili tree, a teak wood tree and three coconut trees near the house were destroyed in the lightning. The anjili and teak wood trees were much taller than the house and close to it. The husband was sitting on a wooden bench while the lightning discharge occurred. There was another slightly taller bench, used like a table on which tea was to be served. The taller bench had a cross bar along the length on which the husband had kept his feet, crossed. His wife at the time of accident was walking from the fireplace in the room to the husband with tea in her hand. Suddenly the wife collapsed, probably electrocuted by step voltage. It was reported that the injured had no burn marks on her body. The exact mechanism of injury to the lady which caused death is not clear because step voltage mostly do not cause death [1]. Other injuries like ones due to fall etc. are known to follow lightning injuries. There is a possibility she was injured in the sudden fall also. The walls of the house cracked due to the lightning discharge. Electrical wiring of the house was destroyed. The coconut trees could have been destroyed due to step voltage. All the trees were in the area just outside the room of accident but the exact distances of the trees were not available. From the report it is understood that all the trees were within a distance of about 15 $\mathrm{m}$ from the room. But which one, the anjili or teak was hit and why the other tree also was destroyed could not be ascertained.

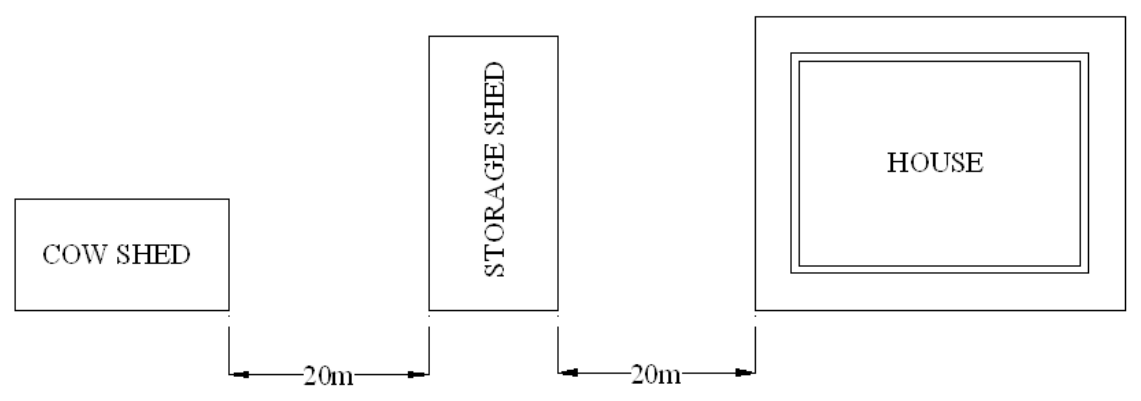

Fig. (11). Plan view of the structures at site G19. 
Of all the ground conduction accidents the one at G19 was an incredible one. The significance of presence of a metal object in the vicinity of a lightning discharge in contributing to the lightning currents is seen in this incident. Probably the suitable description for the involvement of the metal object in this incident would be to say that the lightning discharge 'sought' the metal object which was kept in the inside room of an asbestos roof shed. The G19 location has three structures. The layout of the three structures is shown in Fig. (11).

One is an asbestos roof cow shed. The second one is a storage shed with asbestos roof. The third is the RCC building where the house owner and family live. The structures are in a line and the distance between each is about $20 \mathrm{~m}$. The second one, namely the storage shed where the ground conduction event happened is shown in Fig. (12).

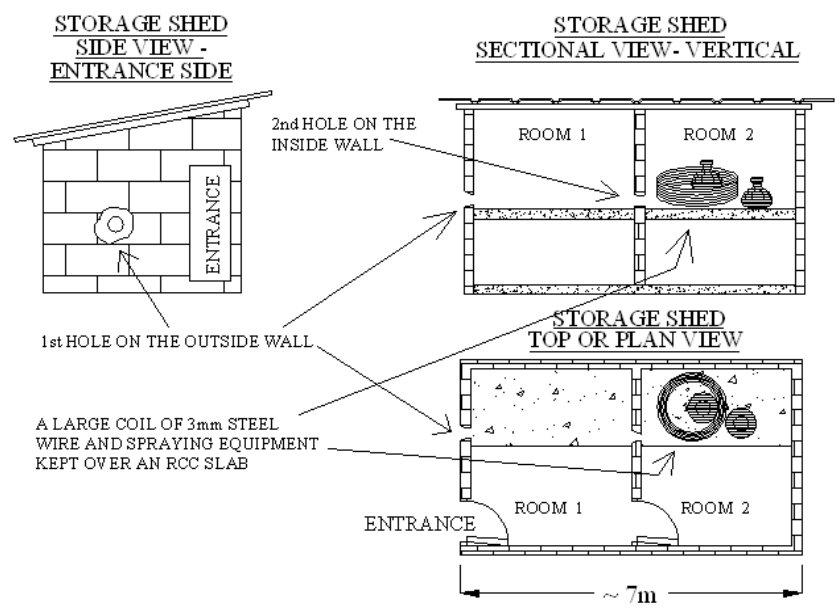

Fig. (12). Side view, vertical sectional view and plan view of the storage shed which was involved in lightning by ground conduction at site G19. The holes on the outside wall of Room 1 and the wall of the inside room namely Room 2 are shown.

The cow shed and the storage shed were involved in the lightning incident. The cow died and the walls of the cow shed developed cracks from the incident. No tree or other tall objects with marks of lightning hit were to be seen in the vicinity. On one side of the structures mentioned trees were present but on the other side no trees were there. Hence it is assumed that the cow shed could be the primary object hit. The storage shed, as shown in the figure, had two rooms and had a continuous RCC slab extending to both rooms. The shed was constructed using hollow cement bricks and had an asbestos roof. After the lightning incident a hole at a height just above the RCC slab in the storage shed appeared out side Room 1. On scrutiny it was found that a similar hole at the same level had appeared on the wall of Room 2 also. In Room 2, on the RCC slab was kept insecticide spraying equipment made of brass and a large coil of galvanised steel wire. It is deduced that the lightning discharge has got connected to the metal objects in Room 2. Since the current from and to the metal objects, possibly, were high the walls developed holes, probably due to Joule heating in a way as given in Rakov and Uman [9]. Considering the route taken and distance covered, the mode of establishment of contact to the coil of wire is quite an uncommon one. Had the conductivity of the steel reinforced slab been sufficient for conduction of current to the coil of wire, it is likely that the holes would not have formed. This is a slightly surprising aspect about the route taken by the discharge current. In this incident overhead pair of wires run between the house and storage shed for providing power connection to the shed was also destroyed.

The events at sites G20 to G22 happened in the same village. Of these the incidents at G20 and G22 are normal ground conduction events. At G20 lightning hit a jack fruit tree and was destroyed. A person standing on the doorway at a distance of $5 \mathrm{~m}$ from the tree was injured fatally. The wall above the doorway was found cracked and the bricks were found exposed with the plastering blown off. The door was only $1.65 \mathrm{~m}$ tall and it is possible that the head of the injured was very close or was touching the door top. It seems the lightning discharge passed through him to the ceiling to cause the crack on the wall over his head. The complete wiring of the house was found destroyed. On inspection the phase wire of the twin, $2 \mathrm{~mm}$ Aluminium conductor pair used for providing connection to the house from the nearest junction was found to have vaporised. The possibility is that the house power earth might have been bad and so the lightning current could establish a much better contact than the house earth at the junction box. The junction box is located outside the house compound and was on top of a lamp post. The junction box could not be inspected.

At G22 a tall 'Choonda Pana' tree was hit and the energy spread by ground conduction to a house $20 \mathrm{~m}$ away. Greyish white marks of arcing could be seen on the house floor. Two people got mild electrical shock from walls by contact and some electrical equipment were damaged. The tree was destroyed.

The G21 disaster was a phenomenal one. This incident is illustrative of the role of metal objects on ground in effecting a higher lightning current. Soil was thrown up several meters high into the air by an explosion on ground. Electrical wiring, electrical equipment and land telephones of nine houses were destroyed because of the involvement of land telephone network. Near the primary objects hit, namely two close by trees, the explosion on ground left a $0.5 \mathrm{~m}$ deep, 1 $\mathrm{m}$ wide and $6 \mathrm{~m}$ long ' $\mathrm{V}$ ' shaped trench. It was reported that blown up soil was found resting on leaves and nodes of rubber trees near the trench. Of the two trees involved one was a very tall anjili tree and the second was a relatively very short coconut tree less than a metre away from the first. The trees were among rubber plants. Upon visit to the site twenty two days after the incident the coconut tree was found dead and dried up. The taller tree looked unaffected as in the case of the jack fruit tree in G7 incident. However it seems the coconut tree, which was shorter than the anjili and rubber plants, got involved either by side flash or by step voltage to its roots. The trench is between the trees and the nearby road. A drawing of the location is given in Fig. (13).

The trench showed an abrupt end near the stub of a cut tree near to the road. The other end of the trench had a smooth tapering to the ground level. A photograph of the trench is given in Fig. (14).

At another point on the edge of the road and near to the poles soil had the look of having been ploughed. This is marked as 'soil found disturbed here also' in Fig. (13). On the near edge of the road was run a multi-core telephone 
cable connected to land phones of nine houses. For protection, the cable was routed through a chain of old, hollow, tapered, galvanised iron (GI) poles of about $12 \mathrm{~cm}$ diameter at the broader end. These poles, each of about $5 \mathrm{~m}$ in length, were not joined together but narrow end was let into the broad end to form a continuous cover for the cable run through it. The poles were in contact with one another and were lying half submerged on the ground to a length of about $100 \mathrm{~m}$. The anjili and coconut trees were at a shortest or perpendicular distance of about $10 \mathrm{~m}$ from the chain of poles and were at a distance of about $15 \mathrm{~m}$ along the trench. The part of the soil where it looked as if ploughed, mentioned above, was at this shortest point to the trees. The energy of the lightning discharge seems to have got connected to this chain of poles and then to the cable inside it and this way entered the nine houses. Because of the involvement of the grounded metal poles, the telephone network of the houses and the power wiring in those houses, the charge collection and dissipation efficiency was very high. Metal objects on ground are known to become instrumental in causing high lightning currents [14]. The cable inside the poles was found burnt and broken. The chain of poles and the connection through the cable to houses seems to have facilitated charge collection from a large area resulting in a relatively high magnitude lightning current. The ground was wet with rain of previous days. The excessive current, possibly long term continuing current seems to have heated the water soaked soil resulting in formation of steam which must have led to an explosion.

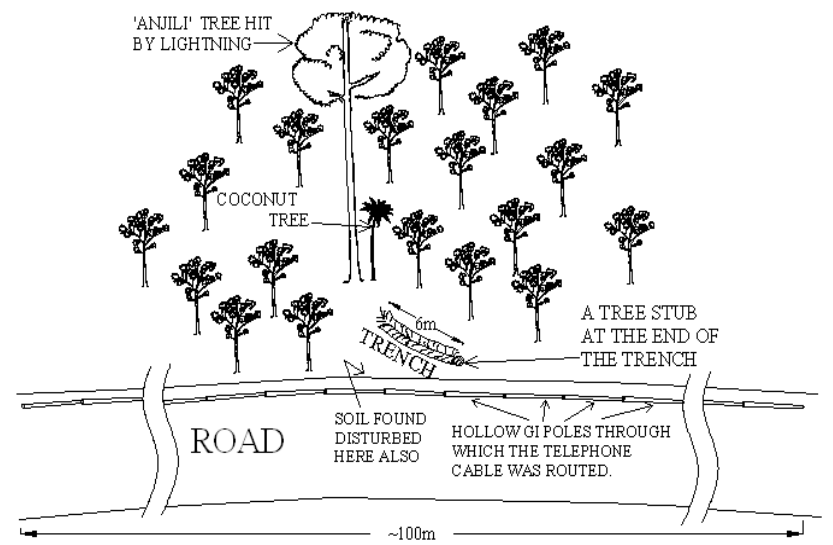

Fig. (13). Depiction of the lightning accident site G21. Heavy lightning current due to the presence of a chain of galvanised iron (GI) poles of about $100 \mathrm{~m}$ length and telephone wires to several houses resulted in formation of a trench of $6 \mathrm{~m}$ length on soil.

The incident listed as G23 is also an interesting one from the aspect of lightning seeking the shortest path for charge dissipation/collection. Also lightning started a fire in this incident. Drawing of the accident site showing the tree and house are shown in Fig. (15).

The incident happened at about $2000 \mathrm{~h}$ local time. The house is located in the coastal plains of the capital city of Thiruvananthapuram. The first visible effect of lightning strike was a burning power meter board (MB) of a house. The MB is at a height of $2 \mathrm{~m}$ above ground and the power earth of the house is just below the MB. A tall coconut tree at about $7 \mathrm{~m}$ away from this earth point was found

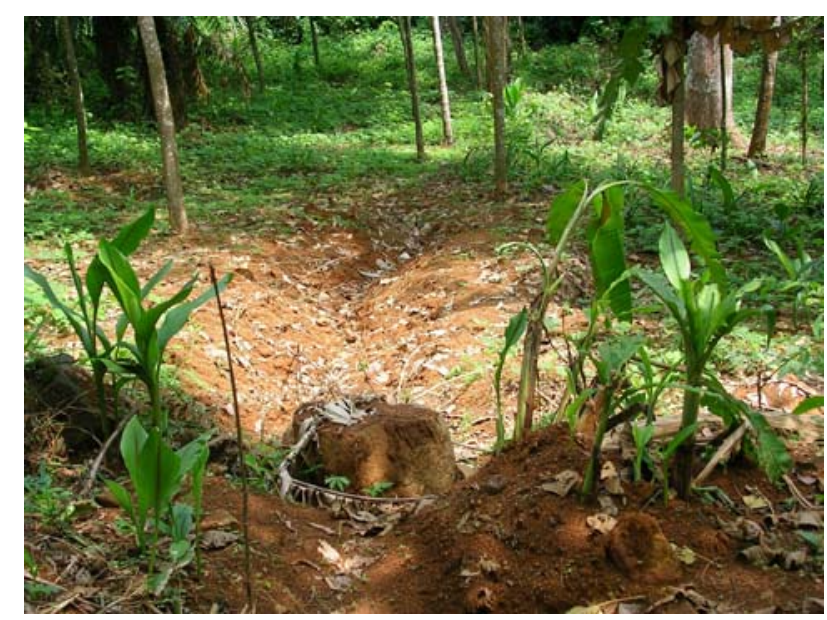

Fig. (14). The trench on soil caused possibly by continuing current at the accident site G21. The anjili tree, the coconut tree and the tree stub which blocked formation of a longer length trench are shown.

significantly damaged. The tree was cut and removed next day. The tree trunk was found split at several places which is indicative of the severity of lightning current. It was clear that the tree was the primary object of strike. The damaged power meter board was on the outer side of a wall. On the same wall but inside the house a small switch board (SB) having two switches, two $5 \mathrm{~A}$ power sockets and a cable TV termination was found damaged. An aspect noticed was that no other wiring or electrical equipment of the house was damaged. On closer inspection a difference in the mode of damages in the MB and SB were noticed.

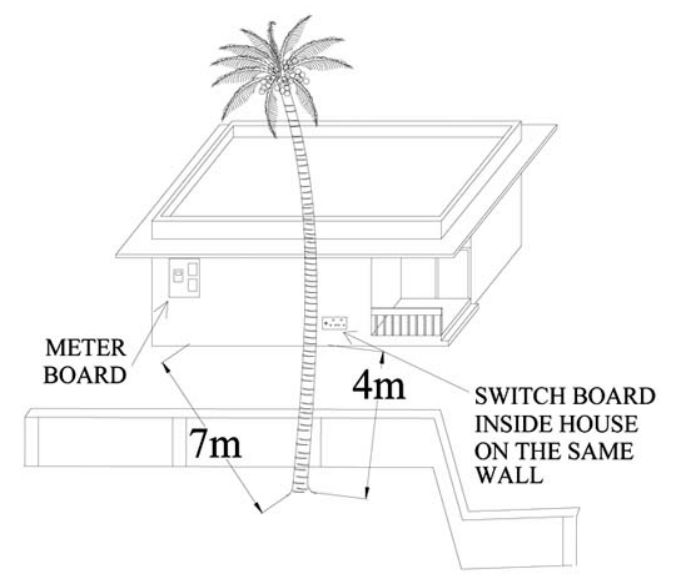

Fig. (15). The G23 location of accident. Power earth, power meter board and location of the switch board inside the house are shown.

At the MB soot of the smoke could be seen only on the top portion of the box. The smoke mark was caused by continuous burning of the electronic power meter which had considerable plastic components. At the SB the soot was found spread in all directions including the down ward direction. This is an evidence of occurrence of an explosion. Photographs of the MB and SB are shown in Fig. (16).

The SB is at a distance of $4 \mathrm{~m}$ from the lightning hit tree and is at a height of $0.75 \mathrm{~m}$ above ground. The explosion at $\mathrm{SB}$, its distance being less than power earth and MB points to the possibility of the SB being the first object which was 


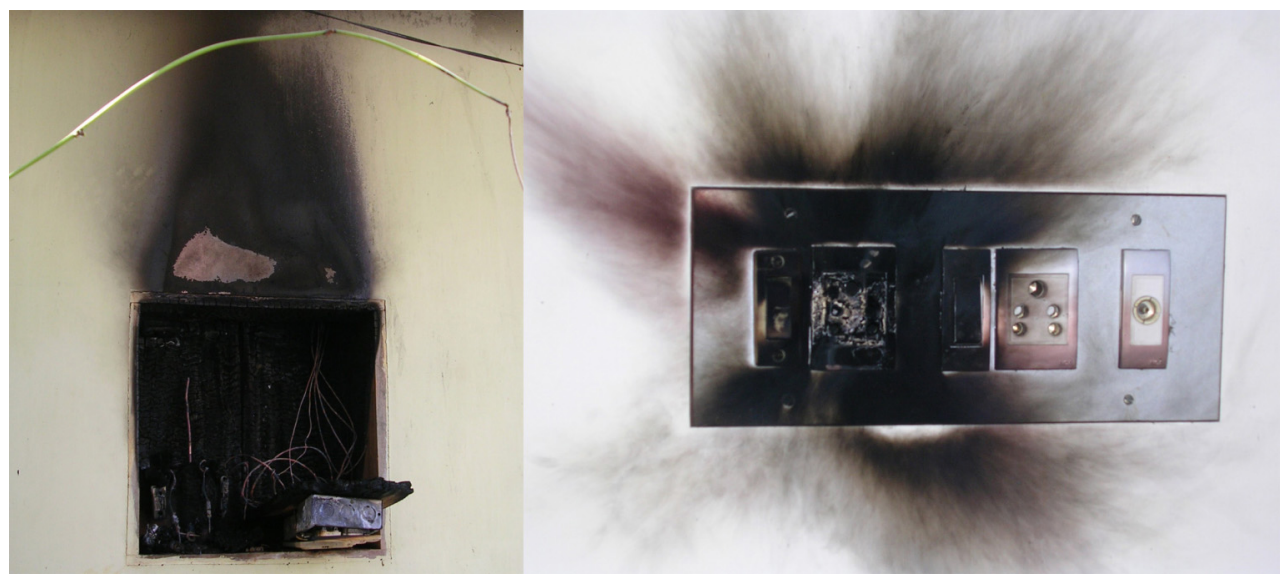

Fig. (16). The damaged Main Power Board (MB) of the house at location G23 is shown in photograph on the left and that of the Switch Board (SB) is shown on the right. It is clear that there was an explosion under SB panel.

involved in the lightning. That no other equipment in the house was damaged is a supporting piece of evidence. Possibly, after involving the SB, the energy got terminated at the MB where good earth connection was available. In other words a high current component of the discharge emanated from the power earth near the MB and through the nearest object, namely the SB got connected to the coconut tree which was the primary object hit. There is one similarity of this incident to the A9 accident. In both cases because a good earth was available to provide sufficient discharge current, rest of the wiring of the house was not damaged. People were present in the house and nobody had any injury and did not feel anything. This shows that upon establishing a good contact with an earth terminal the discharge did not involve any other object in the vicinity as the potential gradient on the floor was insignificant.

The accident at G24 did not have involvement of a tree. Instead of a tree here it was a steel flag mast. Details of the accident site are shown in Fig. (17).

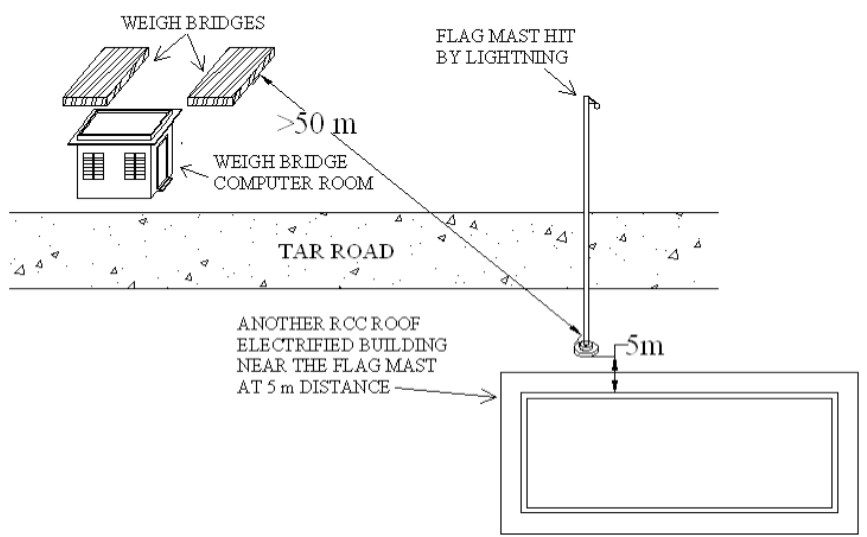

Fig. (17). Plan view of the accident site G24. The flag mast which was hit by lightning, the weigh bridges and the computer room can be seen.

Accident happened inside a Titanium complex factory located in the coastal part of Thiruvananthapuram district. The date of accident was not reported. The result of the accident was destruction of the electronics and computer of both weigh bridges of the factory. Lightning seems to have hit the steel flag mast of the factory shown in the figure. The circular base of the mast, made of bricks and cement, was found broken considerably after the lightning strike. The distance of the nearest weigh bridge to the mast was more than $50 \mathrm{~m}$. Upon careful inspection of the weigh bridge the flexible earth connection ribbon cables of the weigh bridges were found to be mostly corroded. This seems to have resulted in a very ineffective grounding of the weigh bridge mass. An illustration of electrical nature of one load cell of a weigh bridge and strain gauge is shown in Fig. (18).

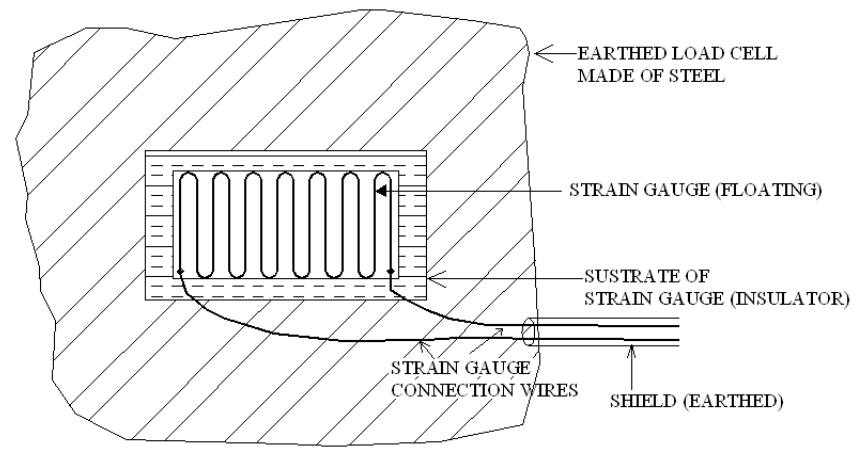

Fig. (18). Illustration of electrical nature of one load cell of a weigh bridge and strain gauge. Wires of the strain gauge going through a shielded cable is also shown.

The strain gauge is normally etched over a substrate which will be a good insulator for voltages at a level used in industrial instrumentation. This is fixed on the load cell made of steel. Several load cells will be supporting the earthed steel platform of weigh bridge and will be in good electrical and mechanical contact with it. Hence normally the voltage that the substrate will have to withstand is the working voltage of the strain gauge of the order of a few Volts. The load cell and the steel platform will be at earth potential. In the accident that is being discussed the load cells and the platform were not earthed well enough. A good earthing would not have allowed raise of potential difference between the load cell and the strain gauge. On the contrary the earthing was ineffective and resulted in the lightning energy entering the strain gauge signal line by breakdown of the substrate insulation.

Another noticeable aspect in this incident is the distance through which the ground conduction has spread to destroy the weigh bridge electronics. As shown in Fig. (17) the 
distance between the mast and weigh bridge is more than 50 $\mathrm{m}$. Also the lightning energy has reached the weigh bridge by ground conduction in spite of the presence of an electrified $\mathrm{RCC}$ roof building only $5 \mathrm{~m}$ away. Regarding the aspect of soil resistivity the factory is close to coast with coastal soil in the premises. The water holding capability of this soil is low. When the water table is only a few meters below surface the volume resistivity can be very low. If the water table is deep the resistivity can be high also. The state of affairs at the time of accident could not be ascertained as it was reported after a period of two months only. This accident is somewhat similar to the G19 accident in the sense that here also the large metal object has got involved possibly because of its relatively high charge collection efficiency.

\section{DISCUSSION}

The mechanism of involvement of people and objects in accidents at $\mathrm{A}$ and $\mathrm{B}$ groups of sites were relatively easy to understand. In the $\mathrm{C}$ group of accidents people were injured in two locations only. These were also relatively simple to understand. The $\mathrm{G}$ group of accidents are in a sense different. These are accidents in which the mechanisms of involvement of objects are not easily understandable as in the case of a direct hit, side flash, contact voltage etc. Probably because of the relatively high vegetation density only that ground conduction accidents happen in these locations. For example the 24 accidents investigated by Kitagawa et al. [12] do not cite a ground conduction event. Considering the accidents at sites G10, G14, G15, G16 and G21 it can be seen that the object hit and the injured victims are far apart. If the tree hit was $50 \mathrm{~m}$ away in G14 it was about $100 \mathrm{~m}$ at G10. In the ground conduction accidents there can be a tendency to assume that there was more than one lightning discharge event to cause damage to the tree involved and the other objects or people. The present investigation indicates that ground conduction seems to be a significant mechanism of involvement in Kerala because of the relatively high vegetation density. Of the total number of 47 accidents presented here 24 are due to ground conduction. It is seen from the $G$ group accidents that houses at distances from $1 \mathrm{~m}$ to $100 \mathrm{~m}$ from vegetation got involved in lightning discharge. In trying to understand the method of propagation in these cases it can be seen that the types of roofs did not have a role in prevention of spread of lightning into the buildings. The fact that power wiring of the house and electrical equipment were always involved indicates that these must have had the role of collection and distribution of charges contributing to the lightning currents. In almost all cases the wires and the conduit having been found broken is a supporting evidence for the charge collection hypothesis.

The G10, G14, G19 and G24 accidents are illustrative of the involvement of large metal objects in lightning. If it was the probing route taken in G19 it was the distance in the case of G10, G14 and G24. The G24 accident can be an example of how equipment can be destroyed if simple and normal safety measures like earthing are not taken care of. Similarly in G21 accident presence of the galvanised iron poles had caused a considerable increase of lightning discharge current to form a wide trench on soil by explosion. Explosions on soil near roots of trees are known to occur [11]. The type of explosion presented here is of a different kind.
In the ground conduction events reported here no building had a lightning conductor installed. A lightning conductor with a $30^{\circ}$ to $60^{\circ}$ protection cone [15-17] could not have prevented any of these accidents as the trees are taller than the buildings by several folds. As the trees are nearby and are taller, the trees have to be protected with lightning rods to prevent a ground conduction accident in the house. This has practical difficulties like attaching a mechanical object to the tender tip of a tree etc. Even if a conductor is installed over a nearby tree another tree slightly distant in a low soil conductivity area can cause damage inside the house. However a ring conductor would prevent an involvement of objects and personnel inside the house.

At G23 and at A9 the lightning hit object got connected to the main power meter board of the house but other parts of electrical power wiring were spared. Possibly because the power earth was present near the main power board to provide a good earth contact for charge collection and dissipation the lightning did not get connected to other parts of the electrical power wiring of the house. In almost all cases where lightning hit object was on the side of the house other than the power earth and power meter board all the electrical power wiring was destroyed. The G20 accident, where possibly the earthing was ineffective, is an exception to this. However it seems that if a well earthed earth terminal were available on the side of these houses where lightning hit tree was present, the possibility of the lightning energy entering the building's electrical wiring would have been minimised.

In the ground conduction accidents presented here objects and personnel at distances from $1 \mathrm{~m}$ to $100 \mathrm{~m}$ from the point of strike were involved. The locations of accidents were of differing soil conductivity. Yet, a relation ship between distance of object or personnel involved and the conductivity of soil is not clearly seen. This is because comparable lightning incidents at locations of differing soil conductivity are few. Nevertheless, almost all the involvements at distances of $20 \mathrm{~m}$ and more, from the point of strike, are in the hilly regions where soil conductivity is low. Many hilly locations have low soil conductivity due to presence of rock close to the surface. The incidents at G12, G13 and G14 had happened at such a hilly region where exposed rocks were very commonly seen. The incident at G14 which resulted in fatal injury of a person may be taken as an illustration of an incident where the low soil conductivity has resulted in fatal injury of a person at a distance of $50 \mathrm{~m}$ from the point of lightning strike. The victim's death can be taken as indication that he had encountered considerable difference voltage. Similarly at G10 a lady having got electrocuted at $100 \mathrm{~m}$ distance also seems to be due to low conductivity of the soil. The injury to the lady was not serious, probably because the difference of potential had become low at this distance. At G24 location also the electronics of the weigh bridge seems to have failed at $50 \mathrm{~m}$ distance because of low conductivity of the soil. As mentioned earlier the soil of this location is of loamy type belonging to high conductivity class but can have very low conductivity when water table is deep. In fact for conductivity surveys during non rainy season it becomes necessary to add salt water near electrodes for necessary contact in this type of soil ${ }^{2}$. The weigh bridge electronics work at voltages less than $20 \mathrm{~V}$ and at currents of the

\footnotetext{
2 John Mathai, Scientist, Geo Sciences Division, Centre for Earth Science Studies, Akkulam, Thiruvananthapuram, India, 2007. Personal communication; email: mathaicess@cessind.org
} 
order of a few milli Amperes. Such equipment can fail at a relatively low difference voltage from the sensor end. Hence the equipment failure at $50 \mathrm{~m}$ from the point of strike is not surprising as the difference voltage required to cause the damage is low and possibly the low conductivity resulted in having sufficient difference voltage.

According to Kitagawa et al. [12] when the lightning current is low it goes through the whole body. Probably this is one of the reasons for fatal injuries in these accidents because in most of the cases the involvement was not direct. Also as suggested earlier in this paper the continuing current seems to have done the most damage.

\section{CONCLUSIONS}

It is seen from the above discussion that $51 \%$ of the accidents have happened because people and objects got involved in lightning due to ground conduction. In areas with high vegetation density as in Kerala the possibility of accident happening due to ground conduction is very high. In all these ground conduction accidents had a lightning conductor been present also the situation would not have been different. In other words a lightning rod would not have protected them. This points to the need for installation of a ring conductor. Summing up, in places of high vegetation density with trees being present almost every where and they being close and taller than the dwellings a ring conductor is essential for protection from lightning. Actually the statistics presented here and analyses of the mechanism of accidents indicate that dwellings in high vegetation areas require ring conductor much more than a lightning rod.

Kerala, because of the presence of Western Ghats mountains with rocky terrain on one side and coastal alluvium on the other side presents a region with widely varying ground conductivity. On locations with low ground conductivity vegetation at distances of more than $50 \mathrm{~m}$ also is found to be dangerous because of the ground conduction involvement. Essentially in devising external protection systems in Kerala and similar places, vegetation density and soil resistivity are of prime consideration.

Presence of metal objects seems to be important in deciding the magnitude of lightning discharge current. Formation of a trench in G21 site seems to prove this aspect. The state of Kerala is a region of relatively high lightning incidence. In such a place leaving a chain of ungrounded metal poles as at G21 and routing a telephone cable through it has to be considered dangerous. The solution could be to ensure that they are joined together and grounded well. G19 and G24 accidents also illustrate the role a large metal object can have in a lightning incident. Large metal bodies may have to be considered as possible objects of involvement in lightning.
Earthing is known to be important from lightning point of view also. However the accidents at A9 and G23 show that most of the house electrical power wiring was saved because of the good earth termination. The G24 and G20 incidents may be taken as cases of destruction where earthing was ineffective.

\section{ACKNOWLEDGEMENTS}

The Director CESS is gratefully acknowledged for the encouragement in conducting these investigations. Sincere thanks to Prof. Rajeev Thottapillil, Upsala University for the fruitful discussions.

\section{REFERENCES}

[1] Lee WR. Lightning Injuries and Death. In: Golde RH, Ed. Lightning. London: Academic Press 1977; pp. 521-43.

[2] Baatz H. Protection of Structures. In: Golde RH, Ed. Lightning. London: Academic Press 1977; pp. 599-632.

[3] GHCC (NASA). Global distribution of lightning April 1995 February 2003 from the observations of NASA instruments, Date accessed: 26 Dec 2005. Available from: www.nasa.gov/centers/god dard/news/topstory/2003/0619lightning.html [Accessed on 26 Dec 2005].

[4] Murali Das S, Sampath S, Mohan Kumar G. Lightning hazard in Kerala. J Mar Atmos Res 2007; 3(1): 111- 17.

[5] Centre for Earth Science Studies (India). Resource Atlas of Kerala. Thiruvananthapuram, India: The Centre 1984.

[6] Telford WM, Geldart LP, Sheriff RE, Keys DA. Applied Geophysics. Cambridge: UK, Cambridge University Press 1976.

[7] Saraoja AK. Lightning Earths. In: Golde RH, Ed. Lightning. London: Academic Press 1977; pp. 577-98.

[8] Kerala State Council for Science, Technology and Environment (India). State of Environment Report Kerala 2005. Thiruvananthapuram, India: The Council 2005.

[9] Rakov VA, Uman M. Lightning Physics and Effects. Cambridge: Cambridge University Press, UK 2003.

[10] Toshio O. Lightning currents. In: Volland Hans, Ed. Hand Book of Atmospheric Electrodynamics. Florida: CRC Press 1995; pp. 93136.

[11] Taylor AR. Lightning and Trees. In: Golde RH, Ed. Lightning. London: Academic Press 1977; pp. 831-49.

[12] Kitagawa N, Tsurumi S, Kinoshita K, Takagi K, Ishikawa T, Ohashi M. The Effects of Lightning Discharges on Human Bodies and the Basis for Their Protection. In: Lothar H. Ruhnke, Latham J, Eds. Proceedings in Atmospheric Electricity, Virginia: A. Deepak Publishing 1980; pp. 318-21.

[13] Magono C. Thunder storms, Elsevier Sc Pub Co., Amsterdam, The Netherlands 1980 .

[14] Mc Eachron KB. Lightning and Lightning Protection. In: Berry Jr. FA, Bollay E, Beers Norman R, Eds. Hand book of Meteorology. New York: McGraw Hill 1973; pp. 264-82.

[15] Golde RH. The Lightning Conductor. In: Golde RH. Ed. Lightning. London: Academic Press 1977; pp. 545-76.

[16] Bureau of Indian Standards (India). Protection of Buildings and Allied Structures Against Lightning- Code of Practice IS 2309:1989. New Delhi: The Bureau 1991.

[17] International Electrotechnical Commission (Switzerland). International Standard IEC 61024-1 Protection of structures against lightning Part 1: General principles, $1^{\text {st }}$ ed.: Geneva: IEC 1990-03. 